\title{
A simple method for short-term (6-hour) transport of the dog heart prior to orthotopic transplantation
}

\author{
E. PROCTOR ${ }^{1}$ and G. MATTHEW S \\ Thoracic Research Unit, Guy's Hospital, London, S.E.1
}

\begin{abstract}
A method of transporting the isolated dog heart for periods of up to 6 hours is described. It consists essentially of flush-cooling the heart with a suitable water-based solution at $4-6^{\circ} \mathrm{C}$. followed by storage in a specially designed portable container which maintains the temperature of the heart at $4-6^{\circ} \mathrm{C}$. The viability of the hearts was tested by orthotopic transplantation. Of nine hearts so stored (six for 6 hours), all supported the recipient circulation immediately after transplantation, with a mean systemic arterial pressure of 70 to $100 \mathrm{~mm}$. $\mathrm{Hg}$ and a mean $\max$. $\mathrm{dp} / \mathrm{dt}$ of the left ventricular pressure of $1,050 \mathrm{~mm}$. $\mathrm{Hg} /$ second without catecholamine stimulation. A comparable group of hearts flush-cooled in the same way but stored in ice after the manner of the method used for kidney transport was markedly inferior in performance to those stored at 4-6 $6^{\circ}$. Some of the limitations of non-penfusion methods of storing the heart are discussed.
\end{abstract}

The practice of moving moribund donors from one hospital to another in order to provide a recipient with a viable organ is no longer acceptable, and the recent embargo on this procedure by some London hospitals has emphasized the point. But the donor organ and the recipient are rarely available in the same place at the same time, and organ transplantation in great part depends upon the use of an acceptable method of bringing the two together. Two such methods are currently in use: (1) the donor organ may be transported to the recipient, as is now common practice in kidney transplantation, or (2) the recipient may be transported to the donor, as is done in some cases of liver transplantation (Calne, 1969). The latter method reduces organ damage to an obligatory minimum, but when the organ to be transplanted is the heart then the complexity of cardiopulmonary bypass systems, the size of the operating team, and the requirements of post-operative monitoring and care make it a more practical proposition to transport the organ rather than the recipient.

Transport involves storage, and although we have developed a hypothermic perfusion method of storing the canine heart in a viable condition for up to 72 hours (Proctor and Parker, 1968), this is more suited to a central heart 'banking' system and is unnecessarily complex and bulky for the purpose of transporting a heart over the short

1Present address: Department of Surgical Sciences, Royal College of Surgeons of England, Lincoln's Inn Fields, London, W.C.2 distances envisaged in the near future. Allowing a fair margin of safety, the maximum storage time need be no more than six hours, and within this limit a simpler, non-perfusion method is the logical choice. The currently popular method of transporting donor kidneys involves preliminary flushing with a cold solution, followed by packing the organ in ice; this is apparently adequate for periods of non-perfusion storage up to eight hours (Hopewell, Blandy, Festenstein, and Moorhead, 1969). However, when we attempted to preserve isolated dog hearts in this way we found that they tolerated the procedure badly, and that after a period of more than two hours in ice the hearts showed signs of damage both in performance and on the electrocardiogram; after four to six hours' storage in ice the myocardium would scarcely perfuse and severe ischaemic damage resulted. This apparent conflict with the results obtained in storing the kidney may be due to the fact that the kidney can sustain considerable damage during storage and yet recover in vivo over a period of days or even weeks (Calne, Pegg, Pryse-Davies, and Brown, 1963). For storage purposes, therefore, the kidney, particularly when complemented by dialysis, can be regarded as a favoured organ. In contrast to this, the heart must work immediately and in full after transplantation; if it sustains more than minor damage during storage, not only will it not recover in vivo but it will, by its effect upon the circulation, quickly exaggerate the damage. Furthermore, 
if it should then fail, there can be no return to the circulatory equivalent of dialysis. It follows, therefore, that more rigorous standards of viability must be applied to the stored heart than are necessary for the stored kidney.

With this in mind we have sought to develop a portable, non-perfusion storage system which would maintain an isolated heart for up to six hours in a viable condition such that it is capable of fully supporting the circulation immediately after orthotopic transplantation.

\section{METHOD}

The experiments were carried out on 18 dogs $(20-$ $35 \mathrm{~kg}$.). Premedication was by morphine $(0.5 \mathrm{mg}$. $/$ kg.) and atropine $(0.01 \mathrm{mg} . / \mathrm{kg}$.) intramuscularly ; anaesthesia was induced with intravenous thiopentone sodium and maintained with halothane and oxygen via a Starling type respirator. After heparinization $(4 \mathrm{mg}$. $/ \mathrm{kg}$.) the dogs were rapidly bled out and the hearts were excised. The hearts were then flushcooled to $4-6^{\circ} \mathrm{C}$. before being placed either in ice $(9$ dogs) or in 4-6 $6^{\circ} \mathrm{C}$. solution (9 dogs) for storage ; the hearts placed in ice were first enclosed within a polythene bag after the manner of the method used in kidney storage (Hopewell et al., 1969). The temperature of $4-6^{\circ} \mathrm{C}$. was chosen as the lowest temperature that would reduce metabolism and yet could be safely maintained with simple apparatus and leave an adequate margin above the freezing point of the solution; it is also a temperature range we are familiar with from our hypothermic perfusion studies. The solution used to flush-cool the hearts was the modified Krebs solution used for long-term perfusion storage of the heart (Proctor and Parker, 1968), with the addition of procaine hydrochloride to a concentration of $0.04 \%$ to induce cardiac arrest and lower the metabolic rate. Volumes of flushing solution were $(a) 7-10 \mathrm{ml} / \mathrm{g}$. at $4^{\circ} \mathrm{C}$. to cool the heart, and $(b) 3-5 \mathrm{ml} . / \mathrm{g}$. at $20^{\circ} \mathrm{C}$., and $3-5 \mathrm{ml}$. $/ \mathrm{g}$. at $35^{\circ} \mathrm{C}$. to rewarm the heart. During the rewarming the cold hearts were never perfused immediately with blood at normal temperature since the myocardium rewarmed more rapidly and evenly, and with subsequent better performance, if this less viscous solution rather than blood was used for rewarming; to aid the removal of procaine from the heart the rewarming solution was procaine-free. Both cooling and rewarming solutions were gassed with oxygen and carbon dioxide to a $p \mathrm{H}$ of $7 \cdot 35-7 \cdot 45, \mathrm{Po}_{2}$ of $3-500$ $\mathrm{mm} . \mathrm{Hg}$, and a $\mathrm{PCO}_{2}$ of $30-40 \mathrm{~mm}$. $\mathrm{Hg}$.

Cardiopulmonary bypass was carried out with a total haemodilution technique using a low priming volume oxygenator of our own design (Proctor and De Bono, 1965) to avoid the problems often associated with homologous blood in dogs (Gadboys, Jones, Slonim, Wisoff, and Litwak, 1963).

Since the principal objective of the study was to assess the capacity of the stored hearts to support the circulation, and as it is our experience with the transplanted dog heart that, haemodynamically, the critical period is immediately following cessation of cardiopulmonary bypass, each experiment was discontinued 3 to 4 hours after transplantation if the circulation was stable. Assessment of the viability of the transplanted heart included the monitoring of is systemic arterial pressure, venous pressure, left atrial $\overrightarrow{0}$ pressure, epicardial electrocardiograms, and the manual measurement of the first derivative of the $\vec{\omega}$ left ventricular pressure, or maximal dp/dtLVP, as an index of myocardial contractility (Hefner, Sheffield, Cobbs, and Klip, 1962). Normal values of i max.dp/dtLVP mean very little in the deeply anaesthetized animal lying on its back with a bilateral thoracotomy and a measure of blood loss, so that each dog was used as its own control insofar as the max.dp/dtLVP of the recipient heart before bypass was taken as an optimum value for the denervated stored heart after bypass.

\section{RESULTS}

The capacity of flush-cooling to reduce the temperature of the myocardium depends not only upon the temperature and volume of the cooling fluid, and the size of the heart, but also upon whether the heart is flushed in situ or after being excised. Figure 1 shows typical cooling curves of the methods of flushing-curve $A$ represents the mean temperature of the left ventricular myocardium of large hearts $(380-420 \mathrm{~g}$.) flush-cooled

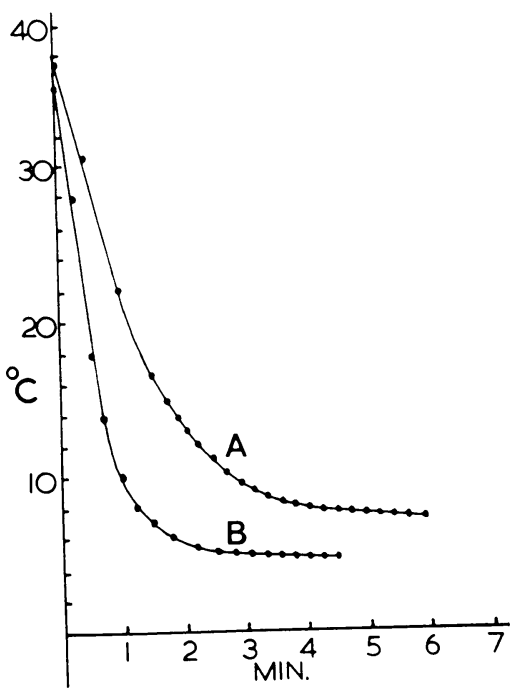

FIG. 1. Typical cooling curves of the left ventricular myocardium of large $(400-420$ g.) greyhound hearts flush-cooled with 3.5 litres of solution at $4^{\circ} C:(A)$ hearts flushed in situ; (B) hearts flushed after excision. 
in situ with the aorta clamped and the ventricles drained, while curve B is a mean cooling curve of comparable hearts flushed after excision. All hearts were flushed with 3.5 litres of solution at $4^{\circ}$ C. Not only did the excised hearts reach a lower minimum temperature more rapidly, but it was found that the whole procedure was more convenient and controllable if the hearts were flushed after excision; this method of cooling was thus adopted for the series.

Figure 2 shows the temperature of the left ventricular myocardium subsequent to flush-cooling

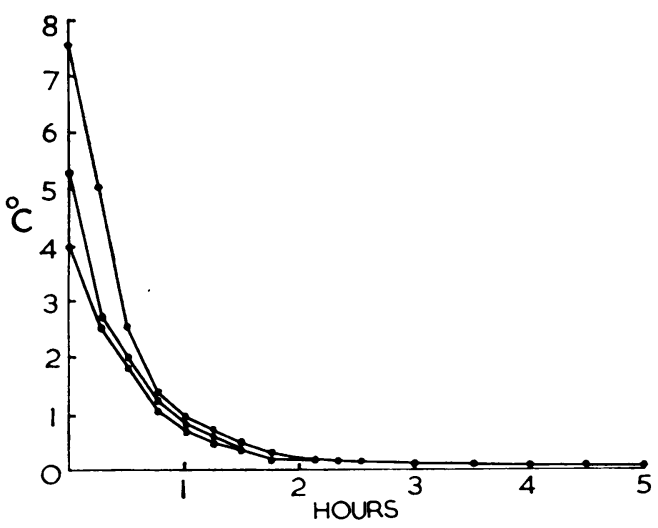

FIG. 2. Temperature of the left ventricular myocardium subsequent to flush-cooling in three hearts stored in polythene bags in ice. Regardless of variation in initial temperature all hearts reached a temperature of $0 \cdot 1-0 \cdot 2^{\circ} \mathrm{C}$. in 2 hours. Storage times of longer than 2 hours in ice were associated with rapidly decreasing viability.

in three hearts stored in ice. Regardless of small variations in the initial temperature, the hearts consistently reached $0 \cdot 1-0 \cdot 2^{\circ} \mathrm{C}$. in 2 hours. This time and temperature are probably relevant to the subsequent performance of the heart in that it was found that with a storage time of less than 2 hours the ice-stored heart was viable (although inferior to the heart stored at $4-6^{\circ}$ C.), but that longer storage times than this resulted in an increasing amount of damage. This is most clearly demonstrated in Fig. 3, where the epicardial electrocardiograms of two ice-stored hearts are compared with those of a control heart (which was excised but not stored) and a heart stored at $4-6^{\circ}$ C. It can be seen that, compared with a control heart, the heart stored in ice for only $2 \frac{1}{2}$ hours shows a marked reduction in amplitude of the atrial and ventricular complexes; this was associated with a poor mechanical performance. After 6 hours' storage in ice it was found that the hearts had a very high coronary resistance and would scarcely perfuse with blood when they were rewarmed ; severe ischaemic damage resulted and terminated in intractable ventricular fibrillation. In striking contrast, hearts flush-cooled in the same way, with the same solution, but stored at $4-6^{\circ} \mathrm{C}$., perfused well and compared favourably with control hearts. Of the nine hearts stored at $4-6^{\circ} \mathrm{C}$. ( 1 for 2 hours, 2 for 3 hours, and 6 for 6 hours), all supported the recipient circulation when transplanted. Without either catecholamines or digitalis, and with the same percentage of halothane anaesthesia (but after 2 hours' bypass), a mean systemic arterial pressure of $70-100 \mathrm{~mm}$. $\mathrm{Hg}$ was maintained after transplantation compared with a mean of $100-120 \mathrm{~mm}$. $\mathrm{Hg}$ pre-bypass. In the transplanted heart the left atrial pressure and central venous pressures were $6-12 \mathrm{~cm} . \mathrm{H}_{2} \mathrm{O}$ and $1-4 \mathrm{~cm} . \mathrm{H}_{2} \mathrm{O}$ respectively. The average maximum dp/dt of the left ventricular pressure of the recipient hearts before bypass was $1,700 \mathrm{~mm} . \mathrm{Hg}$ / sec. (range $900-2,000 \mathrm{~mm}$. $\mathrm{Hg} / \mathrm{sec}$.), and of the transplanted hearts $\left(4-6^{\circ} \mathrm{C}\right.$.) was $1,050 \mathrm{~mm}$. $\mathrm{Hg} /$ sec. (range $700-1,500 \mathrm{~mm}$. $\mathrm{Hg} / \mathrm{sec}$.). These results in the transplanted hearts were recorded without catecholamine stimulation, but the denervated, transplanted heart is markedly sensitive to and benefited by noradrenaline (Cooper, Willman, and Hanlon, 1964 ; Ebert, 1968), and this is clearly illustrated in Fig. 4, where the effect of 3 drops/ min. of a $1 \mathrm{mg}$. $/ 500 \mathrm{ml}$. solution of noradrenaline increased the max.dp/dtLVP of the worst heart from $700 \mathrm{~mm}$. $\mathrm{Hg} / \mathrm{sec}$. to $2,200 \mathrm{~mm}$. $\mathrm{Hg} / \mathrm{sec}$. Figure 4 also illustrates a feature we have often found when testing denervated hearts after longterm perfusion-storage, i.e., the capacity of noradrenaline to 'switch-on' the $P$ wave and initiate sinus rhythm.

PORTABLE BOX The next step was to design a portable version of the above system. Due to the latent heat factor it is a simple matter to maintain a temperature of $0^{\circ} \mathrm{C}$. in a portable container using ice as the cooling agent, but to stabilize a container temperature at $4-6^{\circ} \mathrm{C}$. for some hours without the bulk and complexity of a refrigerator is rather more difficult and usually involves a fine balance between cooling and insulation surfaces. Figure 5 is a cross-section of such a container using ice as the coolant in which these surface areas have been determined empirically. The heat exchange of this container 

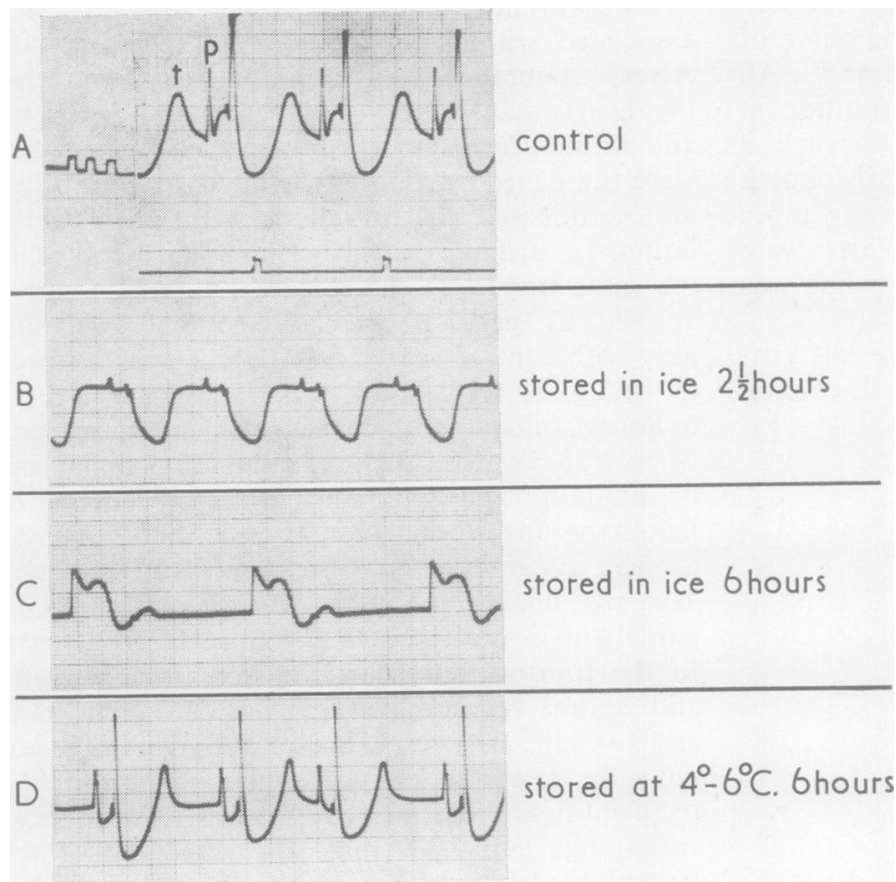

FIG. 3. Epicardial electrocardiograms of isolated hearts connected to the arterio- ${ }^{\infty}$ venous circulation of a support dog. $\overrightarrow{0}$ (A) Control heart-excised and flushedbut not stored. (B) Heart flush-cooled $\vec{\omega}$ to 4-6 $6^{\circ}$. and stored in ice for $2 \frac{1}{2}$ hours. Note marked reduction in atrial and $\times$ ventricular complex; this was associated o with a poor mechanical performance. (C) Heart flush-cooled to 4-6 $6^{\circ}$. and ( $_{\oplus}$ stored in ice for 6 hours. On rewarming $\forall$ the myocardium perfused inadequatelyo and the ECG shows a pattern of severe ischaemia; this was rapidly followed by intractahle ventricular fibrillation $\frac{\subseteq}{<}$ (D) Heart flush-cooled to 4-6 ${ }^{\circ} \mathrm{C}$. and then stored at $4-6^{\circ} \mathrm{C}$. Note similarity to control heart. It supported the circu-o lation after orthotopic transplantation.
FIG. 4. Indicating the sensitivity of the denervated, transplanted heart to noradrenaline using the worst heart of the series. ECG (lead II) and left ventricular pressure in: (A) Recipient heart before bypass and excision (arrow indicates $P$ wave); (B) Donor heart (stored for 6 hours at 4-6 $6^{\circ}$ C.) immediately after orthotopic transplantation. No catecholamines until noradrenaline (3 drops/min. of $1 \mathrm{mg} . / 500 \mathrm{ml}$. solution) given intravenously at $N$; (C) Maximum dp/dtLVP increased from $700 \mathrm{~mm}$. $\mathrm{Hg} / \mathrm{sec}$. to $2,200 \mathrm{~mm}$. $\mathrm{Hg} / \mathrm{sec}$. and appearance of $P$ wave and sinus rhythm (see text).

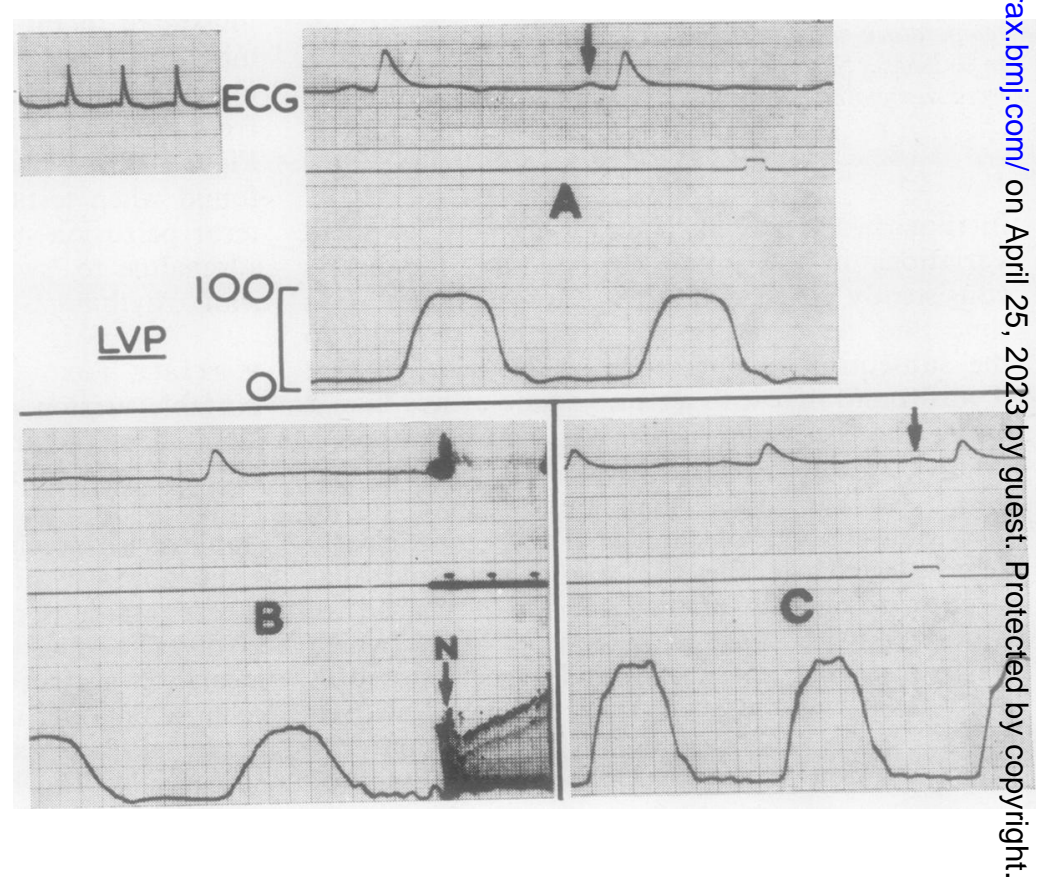




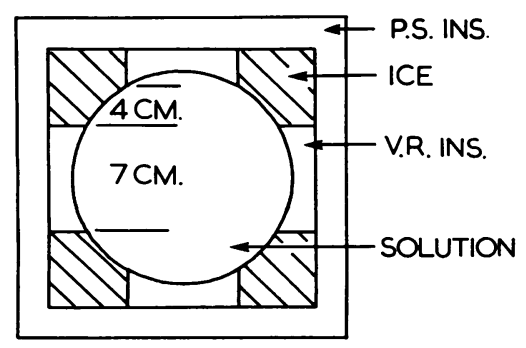

FIG. 5. Cross-section of portable container indicating the proportions of cooling to insulation surface areas (with $\frac{1}{8}$ in. Perpex) necessary to maintain temperature of 4-6 ${ }^{\circ}$ C. for 6 to 8 hours (see Fig. 6).P.S.INS=expanded polystyrene insulation; V.R.INS =vermiculite insulation. The vertical proportions (see Fig. 7) are much less critical.

was designed to be stable at $4^{\circ} \mathrm{C}$. and to remain so until the ice is fully melted-about 6 to 8 hours, depending on the ambient temperature. Figure 6 shows that in such a container a solution with a different starting temperature than $4^{\circ} \mathrm{C}$. will tend towards this value with time, and therefore the system permits of some variation in the starting temperature of the flushing solution, such as may occur if the solution is stored beforehand in a domestic type refrigerator. As a matter of convenience the box serves the several functions

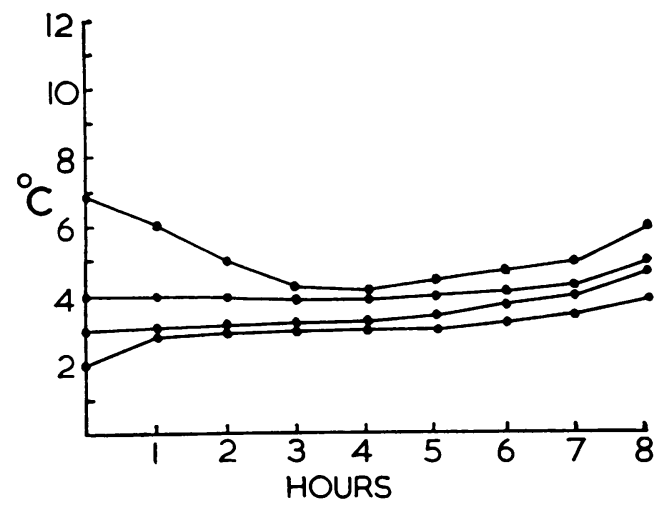

FIG. 6. Temperature of flushing solutions during 8-hour period in the box, with four different starting temperatures. Note stability of heat exchange at $4^{\circ} \mathrm{C}$.

of transporting the cold solution, acting as a flushing reservoir, and finally of transporting the heart at $4-6^{\circ} \mathrm{C}$. in the same solution. These procedures are illustrated in Figure 7.

\section{DISCUSSION}

No particular claim is made for the type of solution used in this series to cool the heart, beyond the fact that it is the same solution that appears to do the heart little harm during long periods of hypothermic perfusion. Some metabolic inhibition stems from the use of procaine and a low calcium content, and the hydrocortisone probably acts by stabilizing the lysosome and cell membranes after the manner of dexamethasone (Yamada, Bosher, and Richardson, 1965). There is little doubt that the informed use of metabolic inhibitors could well extend the safe period of anoxia of the heart, and we are currently evaluating the use of chlorpromazine in this respect.

In spite of the ability of the hearts stored at $4-6^{\circ}$ C. for 6 hours to maintain the circulation after orthotopic transplantation, and therefore to be regarded as 'viable', it must not be forgotten that such non-perfusion or 'ischaemic' methods of storage are inferior to perfusion methods, and that by preventing aerobic metabolism and permitting the accumulation of anaerobic metabolites such methods make great demands upon the myocardial 'reserve'. Although adequate under ideal conditions of excision and insertion (experimentally, the warm ischaemic time rarely exceeded 10 minutes), it is likely that, clinically, due to difficulties associated with the salvage of the donor heart under a variety of conditions, the warm ischaemic period may be extended and further inroads made into the myocardial reserve. This would greatly reduce the non-perfusion storage time available. Until methods for the resuscitation of damaged organs are developed, this period of warm ischaemia is a debt easily acquired and difficult to repay. Greenberg and Edmunds (1961) found that the maximum tolerable ischaemic time (for the maintenance of normal ventricular work capacity) of the normal canine heart is 10 minutes at $37^{\circ} \mathrm{C}$., 15 minutes at $28^{\circ} \mathrm{C}$., 30 minutes at $18^{\circ} \mathrm{C}$., and 60 minutes at $10^{\circ}$. Although this period can be extended somewhat by using pump-oxygenator support after transplantation, the available evidence indicates that the heart sustains significant damage after an anoxic period of more than 30 minutes at $37^{\circ} \mathrm{C}$. Add to this the lower physiological efficiency of the denervated heart due to depletion of its intrinsic myocardial noradrenaline (Willman, Merjavy, Pennell, and Hanlon, 1967 ; Ebert, 1968), and the margin of reserve left for storage damage is narrow. 

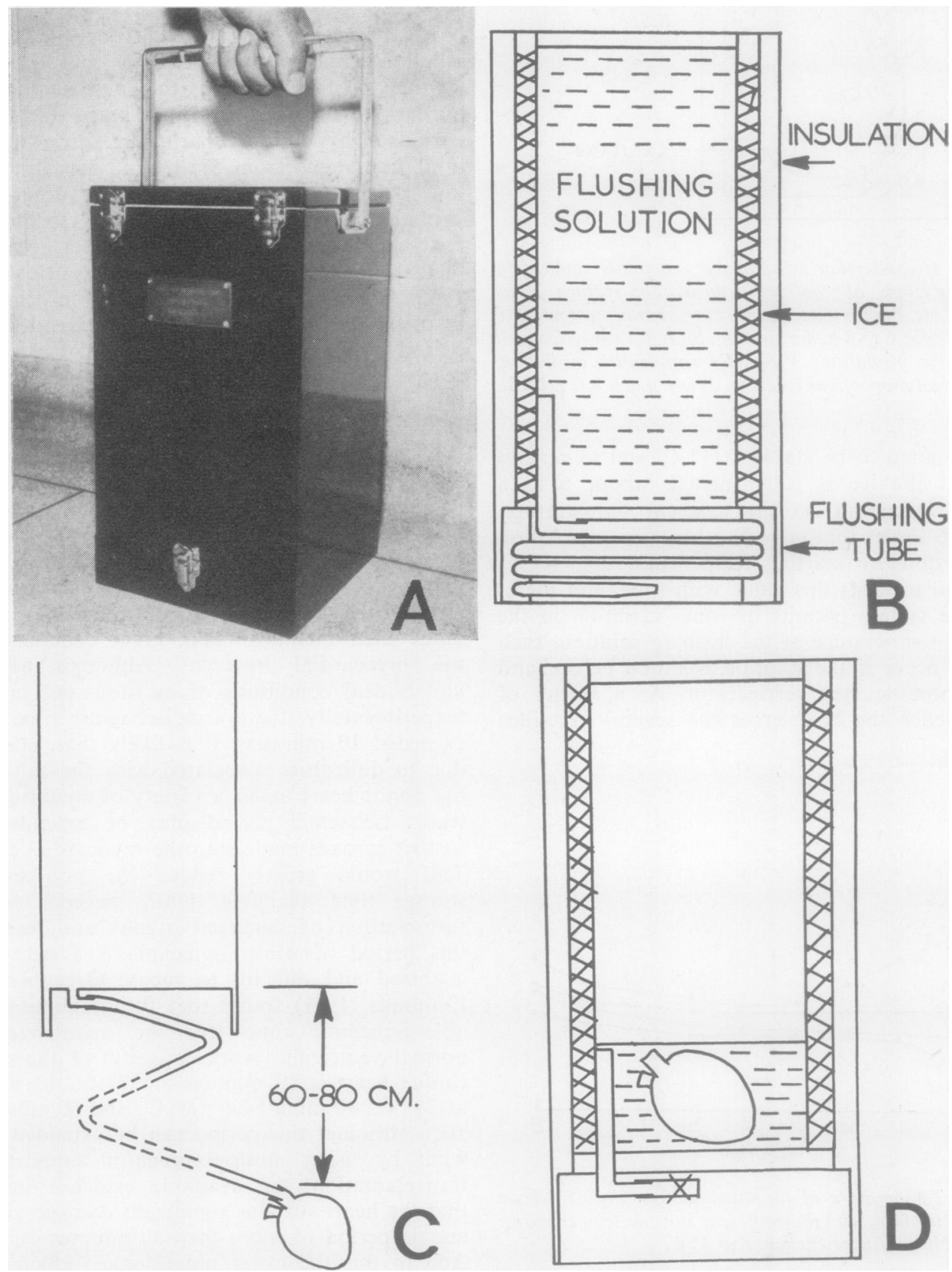

FIG. 7. (A) Portable box for transporting the isolated heart. (B) Diagram of construction (see also Fig. 5). ( $C$ and D) Method of use in flushing and transporting excised heart. 
Within these limits the above method of flushcooling and storage at $4-6^{\circ} \mathrm{C}$. is an adequate and convenient method of storing the isolated heart for up to 6 hours for the purpose of short-term transport of the organ, with the proviso that the warm ischaemic period during salvage does not exceed 10-15 minutes, and is not added to during insertion of the heart. These reservations are made because of the unique requirement that the heart must support the circulation immediately after transplantation. It follows from this that much higher standards of viability during and after storage are required than for other stored organs. Consequently, with the present state of knowledge in this field, if the heart must be stored for more than 6 hours it would be wiser, indeed mandatory, to use a hypothermic perfusion method.

We are indebted to Lord Brock, M.S., F.R.C.S., and Donald Ross, F.R.C.S., for their encouragement and assistance in this work.

We would also like to thank D. Phelan and P. Bostock for enthusiastic technical assistance, and we are particularly grateful to $T$. Jones for his persistence with the many modifications of the transport box.
This study was supported in part by a grant from the British Heart Foundation.

\section{REFERENCES}

Calne, R. Y. (1969). Liver transplantation. Brit. J. Hosp. Med., 2, 1271.

- Pegg, D. E., Pryse-Davies, J., and Brown, F. L. (1963). Renal preservation by ice-cooling. Brit. med. J., 2,651 .

Cooper, T., Willman, V. L., and Hanlon, C. R. (1964). Drug responses of the transplanted heart. Dis. Chest, 45, 284.

Ebert, P. A. (1968). The effects of norepinephrine infusion on the denervated heart. J. cardiovasc. Surg. (Torino), 9, 414.

Gadboys, H. L., Jones, A. R., Slonim, R., Wisoff, G. B., and Litwak, R.S. (1963). The homologous blood syndrome (III). Influence of plasma, buffy coat and red cells in provoking its manifestations. Amer. J. Cardiol., 12, 194.

Greenberg, J. L., and Edmunds, L. H. (1961). Effect of myocardial ischemia at varying temperatures on left ventricular function and tissue oxygen tension. J. thorac. cardiovasc. Surg., 42, 84.

Hefner, L. L., Sheffield, L. T., Cobbs, G. C., and Klip, W. (1962), Relation between mural force and pressure in the left ventricle of the dog. Circulat. Res., 11, 654.

Hopewell, J. P., Blandy, J. P., Festenstein, H., and Moorhead, J. F. (1969). Cooperation in transplantation services. Brit. J. Hosp. Med., 2, 1194.

Proctor, E., and De Bono, A. H. (1965). A low priming volume oxygenator for bloodless priming in cardiopulmonary bypass. Thorax, 20, 540.

- - and Parker, R. (1968). Preservation of isolated heart for 72 hours. Brit. med. J., 4, 296.

Willman, V. L., Merjavy, J. P., Pennell, R., and Hanlon, C. R. (1967). Response of the autotransplanted heart to blood volume expansion. Ann. Surg., 166, 513.

Yamada, T., Bosher, L. H., and Richardson, G. M. (1965). Observations on the autoperfusing heart-lung preparation. Trans. Amer. Soc. artif. intern. Org., 11, 192. 